\title{
A ABORDAGEM DAS CAPABILITIES DE SEN E DE NUSSBAUM: Um estudo comparativo
}

\author{
Tiago Mendonça dos Santos ${ }^{1}$
}

RESUMO: Este artigo tem por objetivo elaborar uma análise comparativa das vertentes da abordagem das capabilities de Sen e de Nussbaum. Para tanto, empreende-se uma revisão da obra de ambos os autores. No artigo são ressaltados os aspectos comuns à perspectiva de Sen e de Nussbaum, assim como são apresentadas, a forma como Sen constrói a abordagem das capabilities, para então apresentar as principais diferenças entre suas propostas em relação a Nussbaum. Destaca-se, no final do texto, que a questão da definição das capabilities relevantes e dos conceitos de direitos para ambos autores podem orientar pesquisas futuras.

Palavras-chave: 1. Capabilities. 2. Functionings. 3. Lista de capabilities. 4. Democracia. 5. Razão pública.

\section{THE CAPABILITY APPROACH OF SEN AND NUSSBAUM: a comparative study}

ABSTRACT: This article has the objective of developing a comparative analysis between the Sen and Nussbaum versions of the capability approach. To do so, both authors will be reviewed. In the article it is highlighted the common aspects to Sen' and Nussbaum's perspectives, as well as it is presented the way how Sen elaborates the capability approach, then the main differences between Sen' and Nussbaum's propositions will be presented. It is pointed, in the end of the text, that the question of selecting the relevant capabilities and the concept of rights for both authors are aspects that may orient future research.

Keywords: 1. Capabilities. 2. Functionings. 3. Capabilities list. 4. Democracy. 5. Public reason.

1 Mestre e Doutorando em Filosofia pelo Programa de Pós-Graduação em Filosofia da Universidade Federal de Santa Catarina (PPGFilosofia/UFSC). Professor do Curso de Direito da Universidade do Vale do Itajaí (UNIVALI). E-mail: mendoncadossantos@gmail.com 


\section{INTRODUÇÃO}

A abordagem das capabilities ${ }^{2}$ é uma proposta que recentemente vem sendo discutida no âmbito da Filosofia Política, assim como em diversas disciplinas do conhecimento. Ela objetiva dar condições para avaliar como as pessoas realmente vivem, ao invés de conceber um ideal de vida humana que deveria ser realizado a partir de algum tipo de estratégia ética, política ou mesmo jurídica.

Do ponto de vista teórico, a abordagem das capabilities contribui com o debate das teorias da justiça, ao propor o foco sobre como as pessoas vivem e sobre quais são suas liberdades, para conduzir seus projetos de vida. Por outro lado, tal abordagem também pode orientar pesquisas em diversas áreas, como o estudo da pobreza e da fome (DRÈZE; SEN, 2002, 2007), avaliações do padrão de vida das pessoas (SEN, 1986, 1999a, 2010) e também para a elaboração e avaliação de políticas públicas ${ }^{3}$ (ROBEYNS, 2006; REGO; PINZANI, 2010).

O foco diferenciado que esta abordagem aporta às teorias da justiça é partir do diagnóstico da existência de diversas injustiças no mundo e dirigir sua atenção à melhoria da justiça e à remoção da injustiça, ao invés de buscar por uma justiça perfeita ou de instituições perfeitamente justas (SEN, 2011, 2017). Assim, ela não busca definir o que é a justiça, ou quais são as instituições justas que conduzem à uma sociedade bem-ordenada ${ }^{4}$. Seu enfoque conduz a uma análise comparativa de diferentes estados existentes ou possíveis a partir do comportamento real das pessoas e da vida que elas podem levar (SEN, 2001).

Dentro desta abordagem destacam-se dois principais referenciais teóricos, Amartya Sen e Martha Nussbaum. Embora as vertentes de Sen e de Nussbaum tenham aspectos em comum, os projetos de ambos rumaram para direções distintas. Sen entende a abordagem das capabilities como o espaço adequado para a avaliação de questões do bem-estar e de justiça (SEN, 2001, 2010), mas entende que não é papel do teórico definir quais são as capabilities que

\footnotetext{
${ }^{2}$ Optou-se pela manutenção do termo em inglês capabilities, tendo em vista que este termo na língua inglesa e especialmente no pensamento de Sen tem um significado mais abrangente do que capacidade (capacity), envolvendo não somente a capacidade, mas também a habilidade necessária para realizar um determinado functioning. Ao longo deste capítulo o significado de capability será melhor explicado (SEN, 2010, 1999a, b).

${ }^{3}$ Nesse ponto, um dos resultados mais notáveis apontados por Crocker e Robeyns (2010) é a orientação dos Human Development Reports, publicados pelo Programa das Nações Unidas para o Desenvolvimento (PNUD), que podem ser acessados a partir do website internacional do PNUD, nas suas edições de 1990 até a última disponível, de 2016 (UNITED NATIONS DEVELOPMENT PROGRAMME, 2018).

${ }^{4}$ Isto é o que Sen (2011) chamou de "institucionalismo transcendental”, definição que não é adotada neste trabalho à luz das críticas apresentadas por Werle (2012).
} 
realmente importam. Já Nussbaum (2000, 2011, 2013), se diz comprometida com a elaboração de uma teoria parcial da justiça, e propõe uma lista de capabilities básicas, definindo de antemão quais são os aspectos que os governos devem priorizar, para garantir que seus cidadãos tenham as condições para se desenvolverem plenamente.

Diante dessas duas vertentes, propõe-se neste artigo investigar quais são os aspectos comuns e quais são as diferenças no pensamento de Sen e de Nussbaum, visando identificar os projetos teóricos iniciados e defendidos por ambos autores e qual a visão que aportam para a abordagem das capabilities. Para tanto, este trabalho se pautará em uma revisão bibliográfica da obra dos autores, valendo-se dos seus comentadores como suporte, quando necessário.

Além desta introdução este artigo está composto em outras três seções, sendo que na seção 2 serão apresentados os principais aspectos em comum entre ambos autores. Na seção 3 será apresentada a abordagem das capabilities especialmente a partir da obra de Amartya Sen. Na seção 4 serão debatidas as diferenças entre Sen e Nussbaum. Este trabalho ainda está composto pelas conclusões do estudo e pelas referências utilizadas nesta pesquisa.

\section{A ABORDAGEM DAS CAPABILITIES}

Os primeiros escritos sobre a abordagem das capabilities datam dos anos 1980, período em que Sen procurou integrar seus trabalhos acerca da pobreza e da fome com as suas críticas ao utilitarismo ${ }^{5}$ e aos seus reflexos na teoria econômica do bem-estar ${ }^{6}$ (SUGDEN, 1986; ROBEYNS, 2005b). Três escritos marcam essa passagem, Equality of What? (EW), de 1980, que consolida o conteúdo das conferências Tanner, de 1979 e outros dois textos publicados originalmente em 1985, Commodities and capabilities, que consolida e estende o conteúdo das conferências Hennipman, de 1982 e Well-being, agency and freedom, de 1985, que consolidou as conferências Dewey, realizadas na Universidade de Columbia no ano de 1984.

\footnotetext{
5 Sen não explicita diretamente contra qual teoria utilitarista ele dirige seus argumentos, havendo poucas referências a autores em suas obras à exceção de Mill, contra quem não chega a dirigir objeções, embora Sen também não faça muita alusão ao Mill utilitarista, e Bentham, que geralmente é criticado. Sen (1999b, 2001, 2010) caracteriza o utilitarismo a partir de três elementos: a) bem-estarismo (welfarism); b) consequencialismo; e c) ranking pela soma (sum-ranking). A partir desses elementos, pode-se caracterizar o utilitarismo criticado por Sen como aquele que ingressou na teoria econômica e serviu de base para a economia marginalista (Jevons, Menger e Walras) e neoclássica (Marshall e Pigou), tratando-se das propostas de Bentham e seus seguidores.

6 “A economia do bem-estar é o ramo da análise econômica que se preocupa com a descoberta de princípios para maximizar o bem-estar social” (BRUE, 2006, p. 393). Destacam-se nesse grupo as contribuições de Walras, Pigou, Pareto dentre outros.
} 
Por sua vez, Nussbaum já era uma reconhecida filósofa pesquisadora da filosofia antiga, particularmente da filosofia aristotélica quando passou a abordar o tema das capabilities. Seus primeiros escritos ainda eram bastante vinculados a uma particular interpretação de Aristóteles feita pela autora ${ }^{7}$. Nessa linha, Nussbaum $(1987,1990,1993)$ já revela uma preocupação em definir quais são os aspectos centrais da vida humana, para a partir destes aspectos definir quais são as realizações elementares para que uma pessoa possa florescer. A vertente de Nussbaum (2000, 2011, 2013) foi particularmente desenvolvida a partir da publicação de Women and Human development: the capabilities approach (WHD) e permanece em Fronteiras da Justiça (FJ) e na sua obra mais recente Creating capabilities: the human development approach (CC). A partir desse momento a autora descreve sua proposta como uma forma de liberalismo político que faz das capabilities básicas espécies de objetivos políticos específicos.

Quais aspectos as vertentes de Sen e de Nussbaum têm em comum? Ou dito de outra forma, quais aspectos caracterizam a abordagem das capabilities? Podemos destacar quatro principais elementos: a) a definição dos functionings e das capabilities e sua relevância como base informacional para avaliações do bem-estar, do desenvolvimento humano ou mesmo da justiça social; b) enfoque nos fins, não nos meios; c) a escolha entre os functionings e capabilities como foco de análise; d) a seleção das capabilities relevantes (ROBEYNS, 2005b, 2006). ${ }^{8}$

Uma primeira distinção enfatizada pela abordagem das capabilities envolve as duas principais variáveis utilizadas para a avaliação do bem-estar de uma pessoa, os functionings e as capabilities. Para os fins desta seção, podemos definir os functionings como as várias coisas que uma pessoa pode fazer ou dos diversos modos como ela pode estar. Trata-se de um conceito que reflete, desse modo, o que as pessoas fazem ou como elas estão (bem ou malnutridas, saudáveis ou doentes, etc.). Já as capabilities, por sua vez, envolvem as reais opções que uma pessoa possui para poder realizar um functioning. Desse modo, ao analisar os functionings, o foco é dirigido às realizações de uma pessoa, enquanto que a avaliação pautada nas capabilities

\footnotetext{
${ }^{7}$ Nussbaum $(1987,1990,1993)$ a denominava uma perspectiva aristotélica, ou seja, baseada no pensamento de Aristóteles, mas não se limitando apenas a uma interpretação da obra do filósofo estagirita.

${ }^{8}$ Além destes quatro aspectos, poderíamos arrolar, ainda, uma quinta característica da abordagem das capabilities, que vem a ser a atribuição de pesos às diferentes capabilities para uma avaliação geral. Neste ponto os escritos de Sen (2004b, 2017) sobre a teoria da escolha social são especialmente relevantes, pois a questão que está em jogo é como traçar os rankings que permitirão uma avaliação geral, ainda que parcial, da situação de uma pessoa (agregação intrapessoal), de um grupo de pessoas ou até mesmo de maiores coletividades (agregação interpessoal). Deixo de considerar este aspecto neste artigo, tendo em vista que ele está especialmente relacionado com as aplicações empíricas da abordagem das capabilities.
}

Revista de Teorias da Justiça, da Decisão e da Argumentação Jurídica | e-ISSN: 2525-9644 | Salvador | v. 4 | n. 1 | p. $22-43$ | 
considera a liberdade que uma pessoa efetivamente possui (ou não) para realizar functionings (NUSSBAUM, 1993, 2003; SEN, 2001, 2010).

Em segundo lugar, destaca-se que a abordagem das capabilities se propõe a dirigir o foco aos fins do bem-estar e do desenvolvimento humano, no lugar dos meios para se alcançar tais fins. O enfoque nos functionings e nas capabilities e não nos bens necessários para se alcançar tal resultado tem esse significado. Essa distinção é enfatizada pela contraposição de Sen e de Nussbaum a teorias que se foquem exclusivamente na distribuição de bens ou de rendas, ou ainda nos bens primários de Rawls (2016) ou nos recursos de Dworkin (2005), os quais são entendidos apenas como meios que não obrigatoriamente conduzirão aos fins desejados (a realização dos functionings, uma sociedade mais justa e com menores níveis de desigualdade, etc.) (ROBEYNS, 2005b, 2009; SEN 1986, 1993, 2001). Como destaca Sen (2001, p. 89): “A capability é principalmente um reflexo da liberdade para realizar functionings valiosos. Ela se concentra diretamente sobre a liberdade como tal e não sobre os meios para realizar a liberdade, e identifica as alternativas reais que temos”.

Em terceiro lugar, surge a questão da escolha entre functionings e capabilities como fundamento para empreender uma análise. Como o nome já diz, a abordagem das capabilities as prioriza em relação aos functionings. Isso significa dizer que essa abordagem valoriza a liberdade de escolha dos indivíduos, não pretendendo previamente determinar qual é o significado do bem, que deve ser perseguido por todos seres humanos. Ou seja, essa abordagem afirma não pretender impor uma noção particular sobre o que é a boa vida, visando, pelo contrário, favorecer todas as possíveis formas de vida que uma pessoa possa valorizar (ROBEYNS, 2006).

Uma quarta característica comum é a seleção das capabilities relevantes. Esse é um aspecto que gerou bastante debate e mesmo críticas à abordagem e à sua utilidade para uma análise moral. Este aspecto marca, também, uma das principais divergências entre Sen e Nussbaum. Ambos autores concordam que existem certas capabilities que são comezinhas, enquanto outras são mais importantes, além disso, algumas adquirem um status moral, enquanto outras não, mas ambos autores divergem, todavia, sobre quem deve decidir quais são os functionings valiosos, como veremos na quarta seção.

\section{A ABORDAGEM DAS CAPABILITIES DE SEN}

Revista de Teorias da Justiça, da Decisão e da Argumentação Jurídica | e-ISSN: 2525-9644 | Salvador | v. 4 | n. 1 | p. 22 - 43 | 
Como Sen e Nussbaum constroem o argumento da abordagem das capabilities distintas, desenvolver a formulação de ambos os autores seria um trabalho extenso, que acabaria impedindo a comparação entre ambas abordagens dentro do espaço deste artigo. Assim, adotase como estratégia apresentar a construção do argumento de Sen nesta seção, para posteriormente correlacioná-lo com a exposição de Nussbaum na quarta seção.

\subsection{O BEM-ESTAR, A AGÊNCIA E SUAS RESPECTIVAS LIBERDADES}

Sen (1985, 1999b, 2001, 2010) parte da distinção entre duas perspectivas sobre uma pessoa: o bem-estar e a agência, considerando que ambas possuem sua relevância para a avaliação individual de estados e de ações. O aspecto da agência envolve a capacidade individual para estabelecer objetivos, comprometimentos e valores, enquanto que o aspecto do bem-estar se relaciona com a satisfação das necessidades pessoais, envolvendo considerações sobre a felicidade ou prosperidade. Dessa forma, o aspecto do bem-estar abrange as realizações e oportunidades do indivíduo no contexto de sua vantagem pessoal, enquanto que a condição de agente vai além e permite examinar as realizações e oportunidades em termos de outros objetivos e valores.

Para Sen (1999b, 2001) a agência e o bem-estar, são interdependentes, embora seja relevante distingui-los especialmente com a finalidade de expandir a noção de realização individual. Ressalta-se, assim, que nem todas as atividades de uma pessoa são dirigidas à maximização do bem-estar, como propuseram os utilitaristas ou os economistas do bem-estar. Conforme o autor: “[...] a concepção das ‘pessoas’ na análise moral não pode ser tão reduzida a ponto de conferir nenhuma importância intrínseca aos seus papéis como agentes, vendo-os ultimamente apenas em termos do seu bem-estar” (SEN, 1985, p. 186, tradução nossa).

O bem-estar, nesse sentido, não é uma base informacional suficiente para explicar, por exemplo, a ação de uma pessoa que abre mão do seu bem-estar pessoal em favor de algum outro valor como o auxílio a uma outra pessoa ou em favor de um senso de cidadania ou de patriotismo. Embora o bem-estar de uma pessoa seja influenciado por sua agência, isto não implica que as informações sobre o bem-estar pessoal representam completamente os aspectos da agência, até mesmo porque certos aspectos, como o dever de cumprir obrigações, podem vir a ter um impacto negativo no bem-estar, tal como os exemplos acima demonstram. 
Desse modo, enquanto o aspecto do bem-estar é particularmente importante para a análise de questões de justiça distributiva o escopo da agência é mais amplo “[...] incluindo a valorização de várias coisas que ela [a pessoa] gostaria que acontecessem e a capacidade de formar esses objetivos e realizá-los” (SEN, 1999b, p. 75). A avaliação da realização da agência se dá a partir do sucesso dessa pessoa em perseguir todos os objetivos que ela tem razão para buscar (SEN, 1993).

Boa parte da crítica de Sen à economia do bem-estar se dirige ao fato de que a sua premissa da racionalidade autointeressada dos agentes econômicos acabou por retirar da análise econômica o aspecto da condição de agente dos indivíduos (SEN, 1999a, c). ${ }^{9}$ O aspecto da agência permite incluir na análise as condições que uma pessoa tem de alcançar o que ela considera valioso, como a liberdade, certos direitos, autonomia etc. (SEN, 2010).

Sen (1985, 1999b, 2001) destaca dois tipos de liberdades, que se relacionam com os aspectos do bem-estar e da agência. Assim, para além da busca pela realização do bem-estar, há uma liberdade de escolha das formas pelas quais esta realização ocorrerá, ou seja, há uma liberdade de bem-estar. Da mesma forma, para além da realização da condição de agente, há uma liberdade para o exercício da agência. Esta conciliação entre a liberdade de escolha do que se quer realizar e à disponibilidade dos meios necessários para realizar esta escolha fazem parte do cerne dos conceitos de functionings e capabilities dentro do pensamento de Sen.

A respeito da integração entre agência e bem-estar Osmani (2009) destaca que a relevância de um determinado espaço dependerá do contexto de avaliação. Enquanto o espaço do bem-estar pode ser justificado para tratar sobre políticas públicas ou nas avaliações a respeito da equidade ou justiça social, uma análise pautada na agência e na liberdade da agência se dirige à autonomia da pessoa para realizar os múltiplos objetivos que ela tem razão para valorizar.

Esta concepção bipartida dos aspectos da agência e do bem-estar e suas respectivas liberdades permite a incursão nos dois conceitos basilares da abordagem das capabilities, os functionings que uma pessoa realiza e as suas capabilities para realizá-los. A proposta de Sen (1985, 2001), segundo o autor, é apresentar uma concepção do bem-estar que, por um lado, não peca por uma objetividade que se afasta dos gostos e dos interesses de uma pessoa e, por outro, não cai em um subjetivismo que impeça qualquer espécie de comparação interpessoal.

\footnotetext{
${ }^{9}$ Destaca-se que a crítica à racionalidade feita por Sen dirige-se especialmente à versão extremada assumida em boa parte da teoria econômica dominante, que concebe a racionalidade como: a) consistência interna das escolhas; b) maximização do autointeresse; ou c) maximização no geral (SEN, 2004b).
}

Revista de Teorias da Justiça, da Decisão e da Argumentação Jurídica | e-ISSN: 2525-9644 | Salvador | v. 4 | n. 1 | p. 22 - 43 | 


\subsection{DEFININDO FUNCTIONINGS E CAPABILITIES}

O bem-estar de uma pessoa, para Sen (1993, 2001, 2010), pode ser concebido como a qualidade do seu estado pessoal, ou seja, em termos do que esta pessoa pode fazer ou estar. Estes são os functionings de uma pessoa, sendo que a vida é composta por um conjunto de functionings inter-relacionados, que compreendem estados pessoais (estar bem nutrido, saudável, não ter vergonha da simplicidade das suas vestimentas) e atividades (comer, ler, ver, etc.). Assim, os functionings compreendem ações ou estados elementares como estar adequadamente nutrido, livre de doenças evitáveis ou da morte prematura, mas envolve também ações ou estados mais complexos, como participar da vida em comunidade, ser feliz, ter respeito próprio, etc. “A asserção é de que os functionings ${ }^{10}$ são constitutivos do 'estado’ [being] de uma pessoa, e uma avaliação do bem-estar tem de assumir a forma de uma apreciação desses elementos constituintes” (SEN, 2001, p. 79).

É do conceito de functioning que se deriva o conceito de capability, podendo-se compreender como o conjunto de condições que permitem os functionings cuja realização é factível para esta pessoa.

No espaço dos functionings qualquer ponto, representando uma n-ésima dos functionings reflete uma combinação dos modos de estar e fazer [doings and beings] relevantes a serem exercitados. A capability é um conjunto dessas nésimas de functionings, representando os vários modos de estar e fazer, sendo que qualquer uma dessas (combinação), pode ser escolhida pela pessoa (SEN, 1993, p. 37, tradução nossa).

A capability, nessa formulação, é compreendida como uma espécie de liberdade substantiva, que permite ao indivíduo realizar combinações alternativas de functionings e de escolher aquela que for de sua preferência, ou seja, uma liberdade para se ter estilos de vida diversos (SEN, 1985, 1993, 2001, 2010). Por essa razão o conceito de capability acaba por ser elementar para se compreender a perspectiva de Sen a respeito da liberdade, no particular, na relação da liberdade com o bem-estar de uma pessoa.

A capability não se limita à noção de capacidade (capacity), nem de habilidade (ability), ela abrange ambas, além dos estados mentais e outros estados subjetivos, como estar saudável, ser alfabetizado, etc., e inclui também circunstâncias externas. Dizer que alguém

\footnotetext{
${ }^{10}$ Tradução modificada.
} 
possui a capability de mudar-se para outra cidade não significa apenas o fato de que ela pode se mudar fisicamente, mas implica em considerar as opções reais que a pessoa possui para fazêlo. É nesse sentido que se afirma que a capability é uma medida do grau de liberdade substantiva que uma pessoa possui, para viver o tipo de vida que ela valoriza (PINZANI, 2009; REGO; PINZANI, 2014).

Os conceitos de functioning e de capability são mais explicitados por um exemplo apresentado por Sem em Desenvolvimento como Liberdade $(D L)$, que diz respeito ao uso de uma bicicleta. Andar de bicicleta significa usar desse instrumento como um meio de locomoção, mas o que faz toda a diferença é a razão que faz com que o ciclista faça uso deste instrumento.

Uma pessoa pode andar de bicicleta para ir trabalhar ou pode usá-la por lazer. Neste primeiro caso, a pessoa pode se valer da bicicleta por não querer fazer uso do seu carro por qualquer razão que a própria pessoa dê a esta escolha, como, por exemplo, em razão de uma consciência ecológica ou por ser mais rápido do que o carro, dado o trânsito da cidade. A bicicleta pode ser usada, ainda, pelo fato de um trabalhador não possuir um carro, pela ausência de transporte público para o trecho desejado ou este, embora existente, é ineficiente, ou ainda, pode-se considerar que a pessoa não possui dinheiro para pagar pela passagem do ônibus, ou o gasto com as passagens consumiria grande parte da sua renda pessoal. Nota-se que a bicicleta é um instrumento que pode realizar functionings para as pessoas, mas a condição do ciclista é que faz toda a diferença, podendo envolver a disponibilidade ou ausência de capabilities do ciclista (SEN, 2010; REGO; PINZANI, 2014).

A capability envolve as combinações alternativas de functionings cuja realização é factível para uma pessoa, envolvendo desse modo a liberdade de realizar functionings. Analisando-se essa assertiva no exemplo apresentado, nota-se que o ciclista consciente possui uma maior liberdade do que o trabalhador, o seu conjunto de capabilities é maior, de modo que ele pode escolher entre diferentes functionings (SEN, 2010; REGO; PINZANI, 2014).

Desse modo, a questão central na avaliação do bem-estar de uma pessoa, para a proposta seniana, é a capability de realizar functionings que são valiosos para a própria pessoa. Reforça-se, dessa forma, a importância não somente da realização do bem-estar (realizar um functioning valioso), mas também da liberdade de bem-estar, entendida como a capability para realizar functionings a partir de uma avaliação de combinações de functionings alternativos que poderiam ser escolhidos (SEN, 1985, 2001). 


\subsection{A IMPORTÂNCIA DOS FATORES DE CONVERSÃO}

A perspectiva de Sen sobre como as pessoas vivem, embora parta do indivíduo, não cai em uma simples generalização de que todas as pessoas satisfazem os mesmos níveis de functionings e são dotadas das mesmas capabilities, como fizera a teoria econômica do bemestar baseada nas comparações interpessoais de bens ou utilidades. Para Sen (1999a) a simples comparação entre as capabilities ou entre os functionings realizados por diferentes pessoas não é uma medida fiel de como essas pessoas vivem de fato ou do que elas fazem. Assim, ao comparar o consumo de pão por duas pessoas, não se possui informações suficientes apenas considerando a quantidade de pães que são escolhidas por essas pessoas. Essas características decorrem das diferenças nos fatores de conversão da renda pessoal em capabilities.

Nesse sentido, destaca-se que uma pessoa que possui algum tipo de deficiência física pode possuir um acesso a bens maior e ainda assim ter menos chances de viver uma vida normal, perseguindo os objetivos que ela valorizar, do que um indivíduo fisicamente capaz que possui um acesso menor à renda. Ou ainda, uma pessoa mais idosa ou mais propensa a doenças pode ter acesso a capabilities menores do que uma pessoa mais jovem ou saudável, que tenha uma renda menor, devido às diferenças conversão de renda em capabilities (SEN, 1980, 2001, 2010).

Os chamados fatores de conversão envolvem tanto aspectos individuais, quanto sociais que resultam em diferenças nas condições que uma pessoa tem de converter os bens que ela possui em functionings. Sen $(2010,2011)$ destaca cinco principais fontes de variação entre diferentes pessoas: a) heterogeneidades pessoais; b) diversidades no ambiente físico; c) variações no clima social; d) diferenças de perspectivas relacionais; e) distribuição na família.

Sen (2011) destaca que a atenção aos fatores de conversão é relevante não apenas para ressaltar as diferenças interpessoais e nos diferentes aspectos institucionais ou sociais que impactam na vida de pessoas que vivem em contextos distintos, mas para deixar claro que essas diferenças podem induzir uma dificuldade na conversão da renda em capabilities, de modo que a ação para o combate das desigualdades não pode se pautar exclusivamente na concessão de renda ou de uma igual distribuição de bens entre as pessoas. ${ }^{11}$

\footnotetext{
${ }^{11}$ Para caracterizar essa distinção Sen (2011) cita uma pesquisa realizada no Reino Unido que verificou que 17,9\% dos indivíduos daquele país viviam em famílias com renda abaixo da linha da pobreza. Para o caso de famílias com um membro que é pessoa com deficiência o percentual sobre para 23,1\%. Agora quando se agrega a desvantagem da conversão e se leva em conta a necessidade de maior renda para melhorar a desvantagem das inaptidões, a proporção de famílias com membros que são pessoas com deficiência vivendo abaixo da linha da
} 


\subsection{O ESPAÇO DE AVALIAÇÃO DAS CAPABILITIES}

Uma questão lançada pela literatura é a dificuldade do uso da abordagem das capabilities para se fazer comparações interpessoais, afinal Sen concebe que os vários modos de estar e de fazer são avaliados no espaço dos functionings e capabilities, mas não traça uma hierarquia de functionings (SEN, 2001).

Sen $(1993,2001)$ responde a esta questão reconhecendo esta diferença de importância entre diferentes capabilities e, mais ainda, entre diferentes functionings, pois alguns deles são de pouco interesse ou importância. Além disso, mesmo os functionings que importam necessitam ser considerados uns em relação aos outros. No entanto, ao contrário do que pensaram seus críticos, estas questões estão longe de serem dificuldades teóricas, pois na realidade elas fazem parte da própria abordagem. Para Sen (1993, 2001) a abordagem das capabilities tem dois principais objetivos: a) identificar quais são os objetos-valor; e b) conceber o espaço de avaliação dos diferentes objetos em termos de functionings e de capabilities.

Sen (1993, 2001) destaca, ainda, que em diferentes contextos de análise os objetosvalor variam tanto quantitativamente, quanto qualitativamente. Ao se lidar com contextos de pobreza extrema em países considerados em desenvolvimento a análise poderá tender a se concentrar em um pequeno número de functionings de importância central e suas correspondentes capabilities, como estar bem nutrido e abrigado, estar livre de doenças evitáveis, da morte prematura, etc. Já em outros contextos, a lista de functionings e de capabilities valiosas poderá ser muito mais longa e diversa.

O autor prossegue destacando que na avaliação do bem-estar os objetos analisados são os functionings e as capabilities, mas isto não implica que todos os tipos de capabilities são igualmente importantes ou valiosos, nem indica que qualquer capability necessita ter algum valor na avaliação do bem-estar de uma pessoa. Este é um aspecto que, inclusive, distingue esta abordagem de outras perspectivas que são baseadas restritivamente nos meios para as realizações e liberdades. A valoração dos functionings e das capabilities, portanto, é parte

pobreza salta para 47,4\%. Isso indica que apenas 1/6 das causas da desvantagem da pobreza podem ser atribuídas à renda menor, enquanto que os demais 5/6 são atribuíveis à desvantagem da conversão.

Revista de Teorias da Justiça, da Decisão e da Argumentação Jurídica | e-ISSN: 2525-9644 | Salvador | v. 4 | n. 1 | p. 22 - 43 | 
integrante da própria abordagem (SEN, 2001). Voltaremos a este tema na próxima seção, ao abordar as principais distinções entre o pensamento de Sen e de Nussbaum.

\section{DIFERENÇAS ENTRE AS VERTENTES DE SEN E DE NUSSBAUM}

Um primeiro aspecto a ser ressaltado é a diferente formação de ambos autores. Sen é um economista que já havia se tornado conhecido por suas contribuições na teoria da escolha social, na economia do bem-estar e também nos estudos sobre a fome e a pobreza extrema, antes de formular a sua versão da abordagem das capabilities, Nussbaum, por outro lado, havia construído sua carreira dedicada ao estudo da filosofia antiga, em especial, da filosofia aristotélica (ROBEYNS, 2005b). Estes diferentes backgrounds são bastante marcantes na exposição de ambos autores, refletem, também, no resultado que ambos pretendem entregar a partir dessa abordagem.

Em segundo lugar, destacam-se os diferentes objetivos de ambos autores. Sen constrói uma abordagem mais abrangente, que é aplicável a múltiplos contextos podendo ser utilizada para investigações sobre questões de justiça social, mas também para orientar estudos sobre a pobreza e a fome, sobre o padrão de vida das pessoas, a avaliação do bem-estar de uma nação ou de certas coletividades ou indivíduos, ou ainda a elaboração e avaliação de políticas públicas. O foco de Nussbaum, por outro lado, é mais explícito e dirigido a uma teoria parcial da justiça, que procura por princípios que deveriam estar presentes em todas constituições e tratados internacionais e que deveriam orientar a ação pública, tratando-se de garantias mínimas exigidas pela dignidade humana (ROBEYNS, 2005a, b; NUSSBAUM, 2000, 2013). ${ }^{12}$

Em terceiro, e talvez a distinção mais relevante, o trabalho de Nussbaum tem pretensões universalistas que Sen não adere. Como destaca Nussbaum (2000, p. 6, tradução nossa): “A abordagem das capabilities é plenamente universal: as capabilities em questão são importantes para todos e cada um dos cidadãos, em todas e cada uma das nações e cada um deve ser tratado como um fim”. Isso reflete no chamado princípio da capability de cada pessoa ou princípio de cada pessoa como um fim, que prescreve que as capabilities que são valiosas para todas e quaisquer pessoas são aquelas que devem ser consideradas pela abordagem das

\footnotetext{
${ }^{12}$ Como destaca Nussbaum (2013, p. 191): “O enfoque das capabilities não é uma doutrina política sobre os direitos básicos, nem uma doutrina moral abrangente. Não pretende sequer ser uma doutrina política completa, somente especifica certas condições necessárias para que uma sociedade seja dignamente justa, na forma de um conjunto de direitos fundamentais para todos os cidadãos” (Tradução modificada).
}

Revista de Teorias da Justiça, da Decisão e da Argumentação Jurídica | e-ISSN: 2525-9644 | Salvador | v. 4 | n. 1 | p. 22-43 | 
capabilities. Sen não apresenta em suas obras argumentos de caráter tão universal, preocupando-se mais na dimensão comparativa de como as pessoas se encontram e de quais capabilities aquelas pessoas valorizam, ao invés de procurar um elenco cultural de capabilities que são valiosas por si próprias (ROBEYNS, 2005a). Essa distinção tem reflexos diretos na posição de ambos autores a respeito da definição ou não de um elenco de capabilities que são por si mesmas valiosas.

Desde seus primeiros escritos sobre o tema, Nussbaum $(1987,1990,1993)$ já revela uma preocupação em delimitar quais são os aspectos centrais da vida humana para, a partir deles, definir quais são os functionings elementares para que uma pessoa possa florescer. De acordo com a autora seria papel do legislador dar condições para que os seus cidadãos realizem estes functionings, de modo que a ação pública estaria voltada à promoção das capabilities centrais para dar este tipo de condição aos indivíduos.

Em seus primeiros escritos sobre as capabilities Nussbaum $(1990,1993)$ se contrapõe diretamente às propostas liberais de Rawls e de Dworkin e a sua defesa da prioridade do justo sobre o bem. ${ }^{13}$ Para a autora uma teoria normativa necessita se basear em uma noção, ainda que mínima, do que é a vida boa, a qual deve captar apenas os aspectos universais de uma definição do que é o ser humano. Nas palavras da autora: “Nós dizemos que uma vida sem esses itens ou estruturas não é reconhecível como humana; e dado que qualquer vida humana que nós podemos desejar para nós mesmos e para os outros é, ao menos, humana [...] isso traça uma linha geral das nossas aspirações” (NUSSBAUM, 1990, p. 224, tradução nossa).

Sen (1993, 2004a, 2010) não adere a esses argumentos, entendendo que a interpretação aristotélica de Nussbaum é um dos possíveis usos da abordagem das capabilities, comprometido com uma concepção de bem previamente definida, mas tal particular interpretação conviveria com outros possíveis usos permitidos pela abordagem. Mais ainda, Sen ressalta que ele próprio não estava desejoso de aderir a um determinado caminho específico, como fizera Nussbaum.

Outra diferença a ser destacada é que Nussbaum não faz o uso da distinção entre as perspectivas do bem-estar e da agência, destacadas na seção 3.1. Nussbaum (2000) reconhece

\footnotetext{
${ }^{13}$ Vale ressaltar que a autora, a partir de Woman and Human Development (WHD), de 2000 demonstra uma reaproximação ao liberalismo político, conciliado com a abordagem das capabilities dela. Conforme Nussbaum (2013, p. 97): “O enfoque das capabilities e o contratualismo rawlsiano são aliados na maioria das questões de justiça. É louvável que teorias com pressuposições e procedimentos tão diferentes gerem resultados tão próximos” (Tradução modificada).
} 
a importância da distinção entre o bem-estar e a agência, assim como as respectivas realizações e as suas liberdades, mas para ela todas estas distinções podem ser encerradas dentro dos conceitos de functionings e de capabilities, enquanto Sen, como visto anteriormente, acaba guardando os conceitos dos functionings e das capabilities como próprios da perspectiva do bem-estar, considerando a agência como algo distinto e à parte. No lugar da agência Nussbaum (1992, 2000) prevê que a razão prática, ou seja, a capacidade de estabelecer planos de vida e de refletir criticamente sobre estes planos é tanto um functioning fundamental (arquitetônico em sua linguagem), quanto também uma das capabilities que integram a sua lista.

Com relação às categorias dos functionings e das capabilities destacam-se algumas distinções entre as propostas dos dois autores. O conceito de functioning para Nussbaum é um mais restrito do que para Sen, especialmente tendo em vista que para ele os estados mentais como a felicidade ou o prazer e seus opostos são espécies de functionings, enquanto Nussbaum, em favor da sua posição aristotélica, considera tais estados como supervenientes a um functioning, ao invés de functionings por si próprios (CROCKER, 1995).

Nussbaum (1990) concebe, ainda, dois tipos de functionings que são arquitetônicos, no sentido de que eles organizam e arranjam todos os demais, conferindo a eles uma característica própria do ser humano. Tais functionings são a razão prática e a afiliação e são considerados mais relevantes que os demais functionings, pois eles podem propriamente designar o que é uma realização humana:

Todos animais nutrem a si mesmos, se movem e assim por diante - e tudo isso como seres individuais. O que é distintivo e distintivamente valioso para nós, com relação ao modo humano de fazer as coisas é que todas essas funções são, em primeiro lugar, planejadas e organizadas pela razão prática e, em segundo lugar, feitas junto de outras pessoas (NUSSBAUM, 1990, p. 226, tradução nossa).

Sen não se preocupa em traçar este tipo de ranking, embora não negue que as necessidades de afiliação e de aceitação dos outros sejam espécies de realizações relevantes. Mesmo relevantes, elas não são centrais da maneira como Nussbaum expõe. Além disso, notase que na perspectiva de Sen não há a preocupação em caracterizar a razão prática como um functioning em especial, até porque seu âmbito se faz manifesto não somente na esfera do bemestar, onde se encontram inseridos os functionings e capabilities, mas também na esfera da agência, como visto na seção anterior. Desse modo, talvez a escolha de Nussbaum em restringir tudo ao espaço dos functionings e das capabilities tenha a obrigado ela a dar um status especial à razão prática em seu sistema, aspecto que, embora não seja ignorado, não é central em Sen. 
No tocante às capabilities, as diferenças entre Sen e Nussbaum são mais pronunciadas, especialmente tendo em vista que Nussbaum introduz três diferentes tipos de capabilities, as internas, combinadas e básicas. De acordo com a autora, capabilities internas são as condições da pessoa (de corpo, mente e de caráter) que permitem que ela possa escolher os vários diferentes functionings que ela valorize (NUSSBAUM, 1987, 1990). Essas capabilities internas envolvem traços de personalidade, capacidades intelectivas ou emocionais, aptidão física e nível de saúde, assim como o que a pessoa já aprendeu ao longo da sua vida e suas capacidades de percepção e de mobilidade (NUSSBAUM, 2011). Ou seja, as capabilities internas são as diversas condições próprias da pessoa que lhe permitem, dentro de um quadro favorável, optar por realizar um determinado functioning. ${ }^{14}$

O que Sen entende como uma capability é definido por Nussbaum como uma capability combinada, que é a totalidade de oportunidades que uma pessoa possui para escolher e para agir em um determinado contexto social e político. As capabilities combinadas abrangem tanto as capabilities internas, quanto as influências do ambiente em que a pessoa se encontra inserida e a situação que ela vive. Para Nussbaum (2011), o conceito de capabilities combinadas é relevante, pois ele aponta para duas tarefas de uma sociedade decente, tais sociedades devem não somente favorecer a produção de capabilities internas pelos seus indivíduos, mas também devem construir condições favoráveis para que as pessoas tenham a oportunidade de realizar seus functionings de acordo com as suas capabilities. De acordo com a autora:

Muitas pessoas que são internamente livres para praticar uma religião não têm a oportunidade de fazê-lo em termos de uma capability combinada porque a liberdade religiosa não é protegida pelo governo. Muitas pessoas que são internamente capazes de participar da política não têm condições de escolher fazê-lo em termos de uma capability combinada: eles podem ser imigrantes sem direitos legais, ou eles podem ser excluídos da participação de alguma forma. Também é possível que uma pessoa viva em um ambiente político e social no qual ela poderia realizar uma capability interna (por exemplo, criticar o governo), mas ela não tem a habilidade desenvolvida de pensar criticamente ou falar publicamente (NUSSBAUM, 2011, p. 21-22, tradução nossa).

Como se nota, esta distinção entre capabilities internas e combinadas é importante para Nussbaum particularmente para fortalecer seu argumento da necessidade da definição de uma lista de capabilities, que deve servir de base para a ação estatal em favor do

\footnotetext{
14 Nussbaum (1987, p. 20-21, tradução nossa) aponta que esta definição de capability interna é inspirada na definição aristotélica de excelência moral (eudaimonia), que foi ampliada para incluir dentro de si outros aspectos do intelecto e do corpo.
}

Revista de Teorias da Justiça, da Decisão e da Argumentação Jurídica | e-ISSN: 2525-9644 | Salvador | v. 4 | n. 1 | p. 22 - 43 | 
desenvolvimento dos seus cidadãos, pois para ela, não é possível pensar na promoção de capabilities combinadas, sem produzir capabilities internas. Por isso, enquanto Sen trata apenas das capabilities Nussbaum procura debater o que cabe ao indivíduo e o que cabe ao Estado, para favorecer o florescimento humano. Verifica-se, no entanto, que o exercício de Nussbaum mais clarifica o significado de ter capability para realizar um functioning, do que propriamente traça um aspecto que não foi considerado por Sen.

Nussbaum $(1987,2011)$ faz o uso, ainda, da categoria capability básica em um sentido diverso daquele proposto por Sen $(1980,1993)$. Enquanto Sen designa como capabilities básicas, aquelas relacionadas com um mínimo existencial, abaixo do qual pode-se afirmar que uma pessoa se encontra em condição de pobreza, Nussbaum considera capabilities básicas o conjunto de aptidões inatas que um indivíduo possui para realizar functionings. Tratam-se de potencialidades que um indivíduo possui, as quais, quando submetidas a um adequado treinamento, à passagem do tempo ou a outras condições podem vir a se tornar capabilities reais, através do treinamento e do desenvolvimento pessoal.

Outra distinção entre ambos autores pode ser traçada na visão que eles apresentam para os direitos em suas teorias. Sen defende uma espécie de análise consequencialista e nãoutilitarista dos direitos, enquanto Nussbaum procura construir sua própria abordagem colocando as capabilities centrais identificadas em sua lista como espécies de direitos (NUSSBAUM, 2000). ${ }^{15}$

Por fim, uma derradeira distinção envolve a definição de a quem cabe o papel de definir quais são os functionings e as capabilities valorizados por uma determinada comunidade de pessoas. Para Nussbaum (2000, 2003, 2011, 2013) é papel do teórico definir quais são as capabilities básicas. Nesse espírito, a autora fornece uma lista de capabilities básicas que deveriam ser distribuídas a todos cidadãos, para que assim eles pudessem escolher as vidas que eles mesmos valorizassem. Para ela, ao não especificar tal lista a abordagem das capabilities poderia incorrer nas mesmas limitações das propostas que ela critica. Desse modo, uma lista objetiva de capabilities básicas poderia ter o poder de criticar as avaliações dos functionings realmente escolhidos pelas pessoas de uma maneira mais robusta do que o procedimento de proposto por Sen. De acordo com a autora:

[...] Sen deve ser mais radical do que ele tem sido nas suas críticas à abordagem utilitarista do bem-estar, introduzindo uma avaliação normativa

\footnotetext{
15 Não pretendo focar essa distinção neste trabalho, que poderia orientar outras publicações sobre as diferentes perspectivas dos autores.
} 
dos functionings humanos e descrevendo o procedimento de avaliação objetiva pelo qual functionings podem ser avaliados pela sua contribuição à vida boa humana (NUSSBAUM, 1987, p. 40, tradução nossa).

Nussbaum procura descrever aspectos que, nas suas palavras, são centrais para as diversas culturas, construindo-se uma definição tão universal quanto possível do que é ser humano e do que é uma boa vida. Esta concepção é definida como essencialista, embora não seja metafísica, porquanto ela não se sustenta sobre uma concepção externa do ser humano (definida em termos biológicos ou a-históricos), nem mesmo está baseada em uma determinada doutrina religiosa sobre o que é o bem. Desse modo, a autora propõe que as diferentes culturas têm condições de preencher o significado das capabilities básicas definidas de acordo com seus próprios modos de vida (NUSSBAUM, 1990, 1995, 2000). Nesse espírito, seu elenco seria empírico e corrigível (PINZANI, 2009).

Embora Nussbaum defenda que sua proposta tenha por objetivo captar apenas os aspectos mais básicos e comuns a todos os seres humanos nas diferentes culturas, O’Neil (1995) aponta para o fato de que esta concepção de Nussbaum acaba por ser muito pouco ampla ou mesmo vaga, como pretende a autora. Para O’Neil a teoria essencialista, ao procurar listar “[...] a totalidade dos functionings que constituem uma boa vida humana” (NUSSBAUM, 1990, p. 209, tradução nossa), acaba por se traduzir em um perfeccionismo moral que concebe que há um caminho para se atingir o bem do ser humano (o alvo), ou seja, há um ideal para a vida, que acaba por restringir as muitas formas pelas quais uma vida pode ser boa, ou mesmo menos boa, sem ser uma vida injusta.

Sen evita seguir a mesma trilha de Nussbaum. De acordo com o autor que o processo de definição das capabilities básicas necessita ser submetido à razão pública e à discussão, de modo que é papel da democracia definir quais são as capabilities julgadas como as mais importantes para uma determinada sociedade (SEN, 2004a). Nas palavras do autor, o problema de uma lista de capabilities é justamente confiar ao teórico, sem qualquer discussão geral, o papel de predeterminar quais são os aspectos mais importantes da vida humana: “Ter uma lista fixa, emanada inteiramente da teoria pura é negar a possibilidade de uma participação pública sobre o que deveria ser incluído e porque” (SEN, 2004a, p. 77, tradução nossa).

Nussbaum (2003) não nega papel à razão pública em sua teoria, mas para a autora a lista de capabilities é submetida à razão pública somente a posteriori. Para ela, é na fase de implementação da lista em cada sociedade que os seus cidadãos poderão participar para dar 
maior substância ao conteúdo já previamente definido na lista. Sen (2004a), por outro lado, considera que este exercício de já entregar uma estrutura "pré-moldada” dos diversos aspectos que deverão ser priorizados é em si um processo de rejeição da liberdade dos cidadãos, sujeitando desta maneira a democracia e a ampla capacidade de participação popular às prioridades definidas pelo filósofo. "O que eu sou contra é fixar uma lista cimentada de capabilities, que é absolutamente completa (nada poderia ser adicionado a ela) e totalmente fixa (não poderia responder à razão pública e à formação dos valores sociais” (SEN, 2004a, p. 78, tradução nossa).

Desse modo, para Sen (2004a) o papel da teoria é apontar qual é o espaço e qual é o procedimento para a avaliação dos diferentes functionings e capabilities. No entanto, não é papel do teórico definir quais são as capabilities relevantes a serem priorizadas, meramente do ponto de vista teórico, sem levar em conta o que as pessoas entendem como mais importante para si mesmas ou o que elas valorizam.

\section{CONCLUSÕES}

O presente artigo foi elaborado no intuito de fazer uma comparação, mesmo que inicial, da forma como Amartya Sen e Martha Nussbaum constroem as suas versões da abordagem das capabilities, que representam os dois principais horizontes para os pesquisadores dessa abordagem.

No intuito de alcançar esse objetivo, foram apresentados neste trabalho primeiramente os aspectos convergentes de ambos os autores, que permitem afirmar que os dois estão vinculados a uma mesma tradição filosófica, que se contrapõe a outras, como o utilitarismo, ou mesmo o liberalismo político, dentre outras. Foi considerada, ainda, a construção de Sen da abordagem das capabilities, para na terceira seção ressaltar quais são os aspectos em que Sen e Nussbaum divergem.

Embora este artigo faça apenas uma apresentação da abordagem em ambos os autores, a partir dessa comparação surgem diversos aspectos que podem orientar novas investigações teóricas a respeito desta abordagem. Destaca-se nesse momento especialmente dois deles, em primeiro lugar, a questão da definição a respeito de quem deve ser o responsável pela definição dos functionings e capabilities considerados valiosos em uma determinada comunidade, o teórico (Nussbaum) ou a democracia entendida como uso público da razão (Sen). Outro ponto que pode 
orientar novas pesquisas é a maneira como Sen e Nussbaum concebem as suas noções de Direito, inclusive as diferentes perspectivas dos autores a respeito dos Direitos Humanos.

\section{REFERÊNCIAS}

ALKIRE, Sabina. Why the capability approach? Journal of Human Development, v. 6, n. 1, p. 115-135, 2005. Disponível em: <https://doi.org/10.1080/146498805200034275>. Acesso em: 14 jul. 2011.

BRUE, Stanley L. História do pensamento econômico. Tradução de Luciana Penteado Miquelino. São Paulo: Thomson Learning, 2006.

CROCKER, David A.; Functioning and capability: the foundations of Sen's and Nussbaum's development ethic, part 2. In: NUSSBAUM, Martha C.; GLOVER, Jonathan. (Ed.). Women, culture and development. Oxford: Clarendon; Oxford University, 1995. p. 153-198.

ROBEYNS, Ingrid. Capability and agency. In: MORRIS, Cristopher W. (Ed.). Amartya Sen. Cambridge: Cambridge University, 2010. p. 60-90.

DRÈZE, Jean; SEN, Amartya. Hunger and public action. Oxford: Clarendon; Oxford, 2002. (Wider Studies in Development Economics).

. (Ed.). The political economy of hunger: entitlement and well-being. Oxford:

Clarendon; Oxford, 2007. 1v.

DWORKIN, Ronald. A virtude soberana: a teoria e a prática da igualdade. Tradução de Jussara Simões. São Paulo: Martins Fontes, 2005.

NUSSBAUM, Martha C. Nature, function and capability: Aristotle on political distribution. WIDER Working Papers, v. 31, 1987.

Aristotelian social democracy. In: DOUGLASS, R. Bruce; MARA, Gerald M.; RICHARDSON, Henry S. Liberalism and the good. New York: Routledge, 1990. p. 203-252.

. Human functioning and social justice: in defense of Aristotelian essentialism. Political

Theory, v. 20, n. 2, p. 202-246, 1992. Disponível em: $<$ http://journals.sagepub.com/doi/abs/10.1177/0090591792020002002>. Acesso em: 03 nov. 2017.

Non-relative virtues: an Aristotelian approach. In: . SEN, Amartya (Ed.). The quality of life. Oxford: Clarendon, 1993. p. 241-269.

Human capabilities, female human beings. In: GLOVER, Jonathan. (Ed.). Women, culture and development. Oxford: Clarendon; Oxford University, 1995. p. 61-104.

Revista de Teorias da Justiça, da Decisão e da Argumentação Jurídica | e-ISSN: 2525-9644 | Salvador | v. 4 | n. 1 | p. 22 - 43 | 
. Women and human development: the capabilities approach. Cambridge: Cambridge University, 2000.

Capabilities as fundamental entitlements: Sen and Social justice. Feminist Economics, v. 9, p. 33-59, 2003. Disponível em: <https://doi.org/10.1080/1354570022000077926>. Acesso em: 25 fev. 2017.

Belknap, 2011.

Creating capabilities: the human development approach. Cambridge; London: The

Fronteiras da justiça: deficiência, nacionalidade, pertencimento à espécie. Tradução de Susana de Castro. São Paulo: Martins Fontes, 2013.

O’NEIL, Onora. Justice, capabilities and vulnerabilities. In: NUSSBAUM, Martha C.; GLOVER, Jonathan. (Ed.). Women, culture and development. Oxford: Clarendon; Oxford University, 1995. p. 140-152.

OSMANI, S. R. The Sen system of social evaluation. In: BASU, Kaushik; KANBUR, Ravi (Ed.). Arguments for a better world: essays in honour of Amartya Sen. Oxford: Oxford University, 2009. 1v. p. 15-34.

PINZANI, Alessandro. Reconhecimento e solidariedade. ethic@, Florianópolis, v. 8, n. 3, p. 101-113, 2009. Disponível em: <https://periodicos.ufsc.br/index.php/ethic/article/viewFile/1677-

2954.2009v8n3p101/21868>. Acesso em: 03 nov. 2017.

RAWLS, John. O liberalismo político. Tradução de Álvaro de Vita. São Paulo: Martins Fontes, 2016. (Biblioteca Jurídica WMF).

REGO, Walquiria Leão; PINZANI, Alessandro. Vozes do bolsa família: autonomia, dinheiro e cidadania. 2. ed. rev. e atual. São Paulo: UNESP, 2014.

ROBEYNS, Ingrid. Selecting capabilities for quality of life measurement. Social Indicators Research, v. 74, p. 191-215, 2005a. Disponível em: < https://link.springer.com/article/10.1007/s11205-005-6524-1>. Acesso em: 24 set. 2017.

. The capability approach: a theoretical survey. Journal of Human Development, v. 6, n. $1, \quad$ p. $\quad 93-114, \quad$ 2005b. Disponível em: $<$ http://search.ebscohost.com/login.aspx?direct=true\&db=a9h\&AN=16295853\&lang=ptbr\&site=ehost-live $>$. Acesso em: 24 set. 2017.

. The capability approach in practice. The Journal of Political Philosophy, v. 14, n. 3, p. 351-376, 2006. Disponível em: <https://onlinelibrary.wiley.com/doi/epdf/10.1111/j.14679760.2006.00263.xepdf $>$. Acesso em: 10 jan. 2018. 
. Justice as fairness and the capability approach. In: BASU, Kaushik; KANBUR, Ravi (Ed.). Arguments for a better world: essays in honour of Amartya Sen. Oxford: Oxford University, 2009. 1v. p. 397-413.

SEN, Amartya Kumar. Equality of what? The Tanner lectures on human values, 1980. Disponível em: < https://tannerlectures.utah.edu/_documents/a-to-z/s/sen80.pdf $>$. Acesso em: 09 abr. 2016.

. Well-being, agency and freedom. The Dewey lectures. The Journal of Philosophy, v. 82, n. 4, 1985

. The standard of living. The Tanner lectures on human values, 1986. Disponível em: <https://tannerlectures.utah.edu/_documents/a-to-z/s/sen86.pdf $>$. Acesso em: 02 nov. 2017.

Capability and well-being. In: NUSSBAUM, Martha; SEN, Amartya (Ed.). The quality of life. Oxford: Clarendon, 1993. p. 30-53.

Paperbacks).

Commodities and capabilities. New Delhi: Oxford, 1999a. (Oxford India

. Sobre ética e economia. Tradução de Laura Teixeira Motta. São Paulo: Companhia das Letras, 1999b. (Prêmio Nobel).

. Desigualdade reeexaminada. Tradução de Ricardo Doninelli Mendes. Rio de Janeiro; São Paulo: Record, 2001.

Capabilities, lists, and public reason: continuing the conversation. Feminist Economics, v. 10, n. 3, p. 77-80, 2004a. Disponível em: <https://doi.org/10.1080/1354570042000315163>. Acesso em: 25 fev. 2017.

Rationality and freedom. Cambridge (MA); London: Harvard University, 2004b.

Desenvolvimento como liberdade. Tradução de Laura Teixeira Motta. São Paulo: Companhia das Letras, 2010. (Companhia de Bolso).

A ideia de justiça. Tradução de Denise Bottmann e Ricardo Doninelli Mendes. São Paulo: Companhia das Letras, 2011. (Prêmio Nobel).

Collective choice and social welfare. $2^{\text {nd }}$ ed. expand. London: Penguin, 2017.

SUGDEN, Robert. Reviewed work: Commodities and capabilities by Amartya Sen. The Economic Journal, v. 96, n. 383, p. 820-822, 1986. Disponível em: <http://www.jstor.org/action/showShelf>. Acesso em: 16 out. 2016.

UNITED NATIONS DEVELOPMENT PROGRAMME. Human development reports. 2018. Disponível em: <http://hdr.undp.org/en/global-reports>. Acesso em: 10 jan. 2018. 
WERLE, Denilson Luís. A ideia de justiça e a prática da democracia. Novos Estudos CEBRAP, São Paulo, n. 92, p. 153-161, mar. 2012. Disponível em: <http://www.scielo.br/pdf/nec/n92/n92a11.pdf>. Acesso em: 10 jan. 2018. 